\title{
A Nova Geografia Cultural de Cosgrove e o grafite como proposta de entendimento da paisagem
}

\author{
The New Cultural Geography of Cosgrove and graffiti as a proposal for \\ understanding the landscape
}

Anderson Akio Shishito ${ }^{\mathrm{a}}$

a Mestrando do Programa de Pós-Graduação em Geografia da Universidade Estadual Paulista "Júlio de Mesquita Filho" (Unesp) - Campus Rio Claro.

E-mail: akiounesp@gmail.com

\begin{abstract}
Sobretudo no atual momento da globalização, os processos de diferentes normas para o espaço urbano e seu próprio uso atribuem maior complexidade ao entendimento da paisagem urbana. A paisagem urbana, em toda sua emaranhada dinâmica, é resultado da transformação e adaptação do meio pela sociedade, traduzindo as características da produção espacial e refletindo segregações e desencontros de tempos históricos materializados. Considerando o grafite como potencial transformador no espaço urbano, buscamos desenvolver a análise desse elemento como proposta de entendimento das noções de paisagens dominantes e alternativas, discutidas por Denis Cosgrove na corrente da Nova Geografia Cultural. Para tanto, o artigo foi organizado em três partes: o grafite na paisagem urbana; o grafite e a cultura como porção simbólica do espaço; e os tipos de paisagem em Cosgrove sob a interpretação a partir do grafite.
\end{abstract}

Palavras-chave: paisagem, grafite, Nova Geografia Cultural.

Especially in the actual moment of globalization, the processes of different norms for the urban space and its uses attribute more complexity to the urban landscape understanding. The urban landscape, in all its entangled dynamics, is the result of the transformation and adaptation of the environment by society, translating the characteristics of spatial production and reflecting segregations and disagreements of materialized historical times. Considering graffiti as a transformative potential in urban space, we seek to develop the analysis of this element as a proposal to understand the notions of dominant and alternative landscapes, discussed by Denis Cosgrove in the current of the New Cultural Geography. Therefore, the article was organized in three parts: graffiti in the urban landscape; the graffiti and the culture as a symbolic portion of space and the types of landscape in Cosgrove under the interpretation from the graffiti.

Keywords: landscape, graffiti, New Cultural Geography. 


\section{INTRODUÇÃO E OBJETIVOS}

O objetivo deste artigo se propõe a analisar a paisagem urbana por meio do grafite, utilizando da temática discutida por um dos principais geógrafos da chamada Nova Geografia Gultural: Denis Cosgrove. Trata-se de buscar elucidar as manifestações do grafite pela conceituação que o autor faz sobre o espaço, sobretudo, no que se refere ao conceito de paisagem.

A partir das noções de paisagens dominantes e alternativas (residuais, emergentes e excluídas) desenvolvidas por Cosgrove, tentaremos refletir sobre como o grafite, tratado como manifestação territorial, pode metamorfosear seu sentido e, desse modo, atribuir valores diversificados à paisagem urbana contemporânea.

Entendemos que o grafite se enquadra como uma materialidade de natureza genuinamente urbana que possibilita a utilização de diversos suportes e configurações imagéticas, sob a égide de uma gama de cultura que utiliza da paisagem urbana para expressar, ser visto e fazer ouvir.

Pensar o espaço urbano é, antes de tudo, entender que a cidade é um organismo com uma multiplicidade de significados: é o lugar de todos os trabalhos, desejos e experiências humanas.

Considerando a cidade como produto e condicionante social, é relevante ressaltar a importância dos aspectos econômicos, políticos e culturais para o entendimento da diversidade socioespacial nela empregada. Esse conjunto de influências, agindo desproporcionalmente no espaço, resulta em uma contiguidade de materialidades distintas e combinadas, produzindo as mais variadas paisagens urbanas.

Entender a cidade pelo arrimo de suas paisagens nos permite a compreensão de diversas características do espaço urbano, considerando aspectos físicos-naturais e humanos. Além da identificação desses aspectos, é importante entender a paisagem urbana como resultado da integração entre: i) o meio físico-natural; ii) a sociedade e os vários grupos sociais que disputam espaço na cidade; e iii) o espaço construído.

Carlos (1994, p. 49) sintetiza a complexidade que permeia a produção das paisagens urbanas quando afirma:

Esse intenso e incansável processo de produção e reprodução humana se materializa concretamente no espaço geográfico e é apreendido na paisagem através de uma serie de elementos: construções, vias de comunicação, plantação, etc. Portanto, percebido e apreendido em sua manifestação formal, a paisagem é a vida cotidiana que é percebida através dela.

Corrêa (2004, p.7) complementa nossa análise afirmando que a cidade é um "conjunto de diferentes usos da terra, justapostos entre si". Tamanha simbiose reflete diretamente na organização socioespacial da urbe e, consequentemente, no processo de segregação socioespacial intrínseca aos grandes centros. Sobretudo no atual momento da globalização, esse processo de diferentes normas e usos do espaço urbano atribui, em conseguinte, maior complexidade à paisagem urbana.

A paisagem urbana se torna, assim, cada vez mais dinâmica - resultado da transformação e adaptação do meio pela sociedade, traduzindo as características da produção espacial e refletindo segregações e desencontros de tempos históricos materializados.

O grafite, assim sendo, tem potencial transformador no espaço urbano, pois rompe com a normatização da paisagem. A normatização da paisagem urbana é orientada pela hegemonia econômica, política e cultural vigente e, desse modo, dita os padrões estéticos - homogeneizados e hierarquizados - nos lugares.

Apoiaremo-nos em Cosgrove (1998) quando reflete sobre os diferentes tipos de paisagens, distinguindo-as em dominantes e alternativas ${ }^{1}$ para analisar a padronização paisagística criada pela força dos agentes hegemônicos vigentes na cidade. Desse modo, acreditamos que o grafite, em contrapartida à paisagem tida como dominante, apresenta-se como expressão ativa na contraposição desse arquétipo, pois introduz novas sensações à paisagem urbana.

Seja por atividades duradouras ou efêmeras, o fato é que a força de atuação do grafite, personificada pelos grafiteiros, compõe o espaço urbano cujos símbolos estão postos para serem interpretados.

Acreditamos que o entendimento desse fenômeno por meio da paisagem nos proporciona formas profícuas de interpretar o espaço, como refletir sobre a comunicação entre homem e espaço, sobre como ocorrem esses diálogos e sobre formas de apropriação a partir da concepção individual de cada um.

No sentido de melhor estruturar nossa proposta de análise, iniciaremos discorrendo brevemente sobre a história do grafite na paisagem urbana para, depois,

1 Esses conceitos serão detalhados no decorrer deste artigo. 
conceituar nossa proposta teórica, a fim de atribuir uma possível reflexão sobre a ação e produção do grafite em diferentes partes da capital paulista, articulando como essa materialidade pode transfigurar seu sentido de acordo com a forma que é cooptada ou atribuída às diversidades urbanas, produzindo marcas singulares na cidade.

\section{Metodologia}

Por meio de revisão bibliográfica, inicialmente, discutiremos a origem epistemológica da Nova Geografia Cultural, para assim chegar ao conceito de paisagem em Cosgrove e seu desdobramento em paisagem dominante e alternativa. O artigo também conta com impressões do autor referente à interpretação de dados primários e secundários coletados em diversas fontes em que o grafite é recorrente.

\section{O grafite na paisagem urbana: $d a$ marginalidade às galerias de arte}

O grafite ${ }^{2}$ é um fenômeno urbano que compõe e propõe uma relação viva, direta e de fácil assimilação com a cidade. Arte para uns, poluição visual para outros, a evidência é que os grafites já fazem parte do cotidiano urbano dos grandes centros. Sendo o grafite uma forma de expressão genuína ${ }^{3}$ do indivíduo que o produz em consonâncias com suas experiências cotidianas, a dialética socioespacial, que se apresenta nele, torna-o importante instrumento de representação da cidade ou das diversas cidades dentro da paisagem urbana. Desse modo, vemos o grafite como uma ferramenta operacional para o entendimento da cidade entre a diversa gama de materialidades que a compõe.

2 O nome "grafite" deriva do termo graphium, uma espécie de grande estilete dotada de uma ponta afiada que propiciava a escrita a partir de sua fricção contra as paredes do antigo império romano (GITAHY, 1999).

3 Compartilhamos da reflexão feita por Mauricio Villaça (GITAHY, 1999) quando discorre que os grafites são como a continuação das garatujas - traços aparentemente sem nexo - que fazemos desde as mais tenra idade e, desse modo, diz respeito a uma necessidade humana de comunicação, como dançar, falar, dormir, comer etc. Essa produção é indissociável da liberdade de expressão, todos os segmentos sociais podem vir a ser lidos pela prática do grafite.
As primeiras inscrições consideradas grafite provêm da cidade romana de Pompeia ${ }^{4}$ (MITTMANN, 2012). Apesar disso, foi apenas em meados do século $\mathrm{XX}$ que essa forma de linguagem tomou rumos mais similares aos que observamos hoje. Em maio de 1968, durante as revoltas dos movimentos estudantis france$\mathrm{ses}^{5}$, o grafite representou uma importante ferramenta de propaganda de ideias políticas libertárias. Os muros de Paris foram tomados pela escrita política, comunicando a população sobre variadas situações, como as campanhas eleitorais formais (divulgação do nome de políticos), eleições sindicais, exposição de ideias libertárias e convocações para atos e manifestações políticas públicas. Frases que se tornaram celebres posteriormente como "Il est interdit d'interdire" ""é proibido proibir"), "demandez l'impossible" ("exija o impossível") e "faites l'amour, pas la guerre" ("faça amor, não faça guerra") são oriundas desse momento (FIGURA 1).

Porém, a popularidade do grafite nos moldes, a partir da qual se tornou universalizado, surge nas ruas de Nova Iorque no final dos anos 1960, mais precisamente, nos bairros do Bronx, Harlem e Brooklyn - redutos de negros e latinos. Esses bairros, que manifestavam problemas, como extrema pobreza, violência, racismo e tráfico de drogas, tornaram-se reduto do grafite. $\mathrm{O}$ grafite surge como um dos elementos base da cultura hip hop, que incorpora dança, música e artes plásticas à linguagem e às necessidades das ruas (GOMES, 2012). Oliveira e Tartaglia (2009, p. 60) explicam a gênese do movimento Hip hop da seguinte forma:

A cultura hip-hop tem como seu epicentro a cidade de Nova York nos anos 60/70, especialmente no Bronx, como uma prática reconstruída pelos imigrantes jamaicanos que

4 Em Pompeia (cidade do Império Romano), foram encontradas escritas desse tipo. De acordo com Mittmann (2012), a cidade esteve desaparecida após a erupção do vulcão Vesúvio em 76 d.C. Por deixar a cidade em cinzas, essa erupção manteve Pompeia oculta por 1600 anos deixando, assim, intactas as escritas nos muros da cidade, que serviram como um vasto acervo para o entendimento das relações políticos-sociais da época.

5 Os movimentos estudantis referidos aconteceram no âmbito de uma greve geral instalada na França, iniciada por estudantes universitários, a favor de uma transformação social que visava, entre outros fatores, a modernização dos costumes presentes na "velha" sociedade francesa, contando, inclusive, com a participação do filósofo Jean-Paul Sartre (MITTMANN, 2012). 
criavam uma nova forma de convivência social nos guetos através das suas antigas festas de rua, as chamadas sound-systems. Essas festas criavam espaços de celebração da multiplicidade que atraía jovens para a diversão e o encontro com os imigrantes porto-riquenhos, mexicanos, haitianos e afro-americanos, entre outros, que assim transferiam os conflitos violentos entre as gangues, ou seja, uma geopolítica urbana de disputas territoriais para as disputas musicais (os desafios de rap), disputas de dança (as batalhas de street dance e break) e as disputas estéticas visuais (competições de quem fazia os melhores desenhos e os mais difundidos pela cidade, os graffitis). Neste sentido, criavam práticas espaciais conciliatórias através de elementos culturais.

Figura 1. Escrita política durante a revolta dos movimentos estudantis franceses ${ }^{6}$.
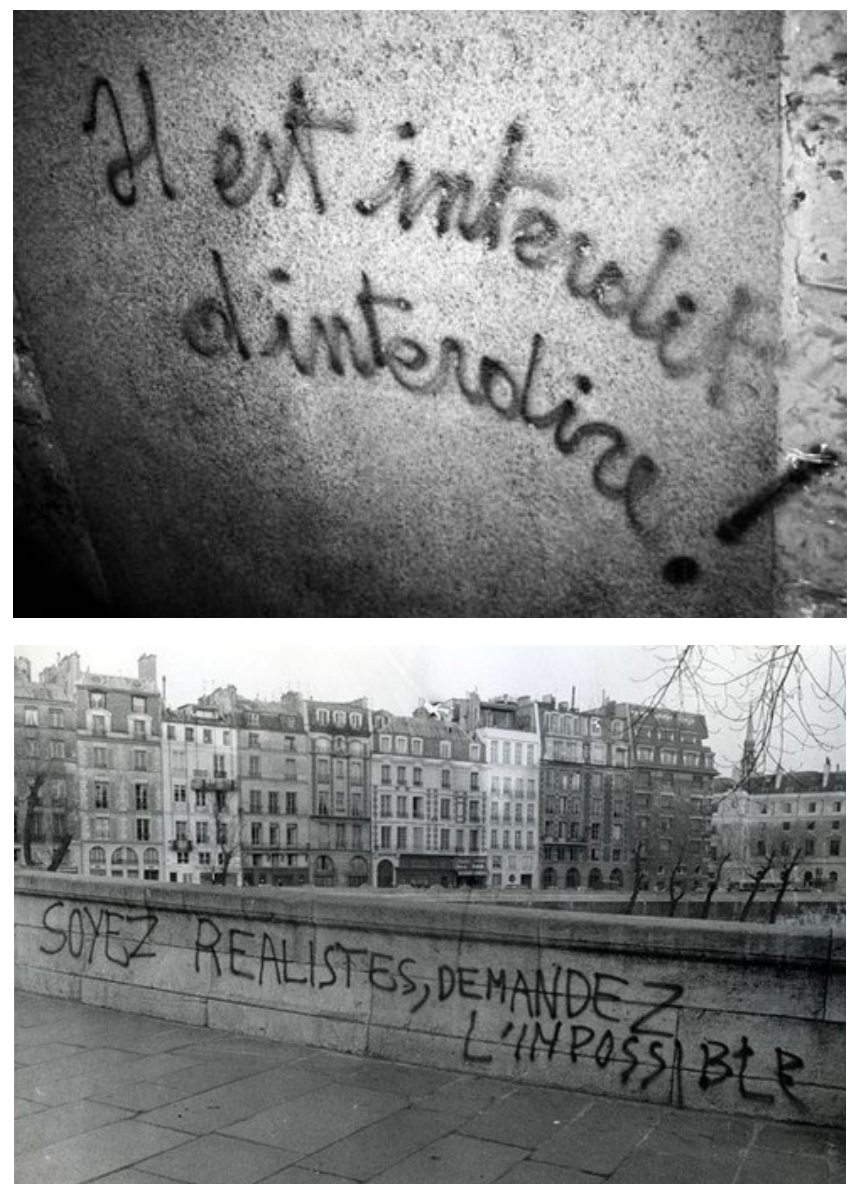

O grafite das ruas de Nova Iorque aliou uma estética própria, contestadora e transgressora que se espalhou como forma e conteúdo para todo o mundo.

6 Imagens disponíveis respectivamente em <http://bit. ly/2szv6UU $>$ e $<$ http://bit.ly/2rKVWX5>.
No Brasil, são as ruas de São Paulo que vão ser palco, pela primeira vez, do que aqui se convencionou chamar de grafite/pichação ${ }^{7}$. Assim como na França de maio de 1968, na capital paulista as intervenções de cunho político se tornaram importantes instrumentos de enfrentamento aos "anos de chumbo" da ditadura civil-militar brasileira (1964-1985). Foi na década de 1970, porém, que o grafite se incorporou à paisagem urbana apresentando diferentes formas e motivações. Tratavam-se de pichações poéticas, intervenções pela técnica do stencil art ${ }^{3}$ - com reprodução seriada - e grafites de autopromoção e com motivações comercias, como é o caso do "Cão Fila K26", mostradas na Figura 2.

Na década de 1980, uma nova forma de escrita urbana eclode pelas ruas dos grandes centros: a pixação. Fazse importante apontar que diferenciar grafite de pixação exige um esforço que vai além de sua concepção estética. Essa distinção passa pelo tratamento diferenciado que seus respectivos autores acabam recebendo a partir de suas práticas, mesmo que a lei estipule um tratamento semelhante para grafiteiros e pixadores. O grafiteiro, diferentemente do pixador, principalmente ao longo da última década, conseguiu ampliar a aceitação de sua prática pela cidade,

7 É importante entender, nesse momento, a pichação como toda e qualquer grafia aplicada, de maneira não autorizada, nos mais variados espaços públicos. Dentro desse amplo espectro de pichações (letras, palavras, frases, desenhos, signos diversos etc.), desenvolveu-se uma maneira de escrita em particular, a qual, para se diferenciar das demais, os "pixadores" adotaram o termo "pixação" com "x". Neste artigo, usaremos as duas grafias, sendo "pichação" para tratar de toda essa gama de pichações e "pixação" com "x" e em itálico para tratar das pichações com a proposta diferenciada dos pixadores, que deixam um lugar com sua marca, até por meio de códigos.

8 Essa pichação ganhava vida pelas mãos de jovens da classe média envolvidos com expressões artísticas compreendidas no campo da vanguarda. Esses jovens experimentavam novas e mais baratas formas de publicização de seus trabalhos e perceberam na nascente técnica do stencil uma econômica oportunidade de espalhar ideias e expressões poéticas pela cidade (MITTMANN, 2012, p. 24).

9 A pichação Cão Fila Km 26 era feita por um senhor conhecido como "Tozinho" e é conhecida como a "pré-história" da pichação de São Paulo. A prática se alastrou por outros estados e, hoje, aparece até na região portuária da cidade de Manaus. Sua escrita pichadora era motivada por seu estabelecimento que criava e vendia cachorros da raça Fila brasileiro, porém, pela forma indireta de comunicação, várias interpretações foram possíveis pela sociedade civil, chamando atenção até mesmo das autoridades militares dos anos de ditadura. 
desvinculando-se da imagem de vandalismo à qual muitas vezes esteve associado. Por outro lado, o pixador continua sendo reconhecido nos diferentes setores da sociedade como vândalo. O mais interessante é notar que os próprios pixadores procuram manter essa reputação e reconhecem suas ações como uma afronta aos valores estéticos e paisagísticos hegemônicos nas cidades (MITTMANN, 2012). É importante ressaltar, também, que muitos pixadores e grafiteiros não consideram que uma prática é evolução da outra (OLIVEIRA; TARTAGLIA, 2009).

Devido a seu caráter transgressor de ocupação do espaço público, a pixação é pouco compreendida até os dias atuais, pois, diferente das expressões urbanas que a antecedem, é um movimento de escrita direcionado aos próprios atores desse movimento. É um código-território fechado: o pixador marca, apropria-se de um espaço físico, entretanto, essa comunicação circula apenas entre os demais pixadores (MITTMANN, 2012), conforme mostra a Figura 3.

Figura 2. Stencil art de Alex Vallauri e pichações Cão Fila K26 ${ }^{10}$.
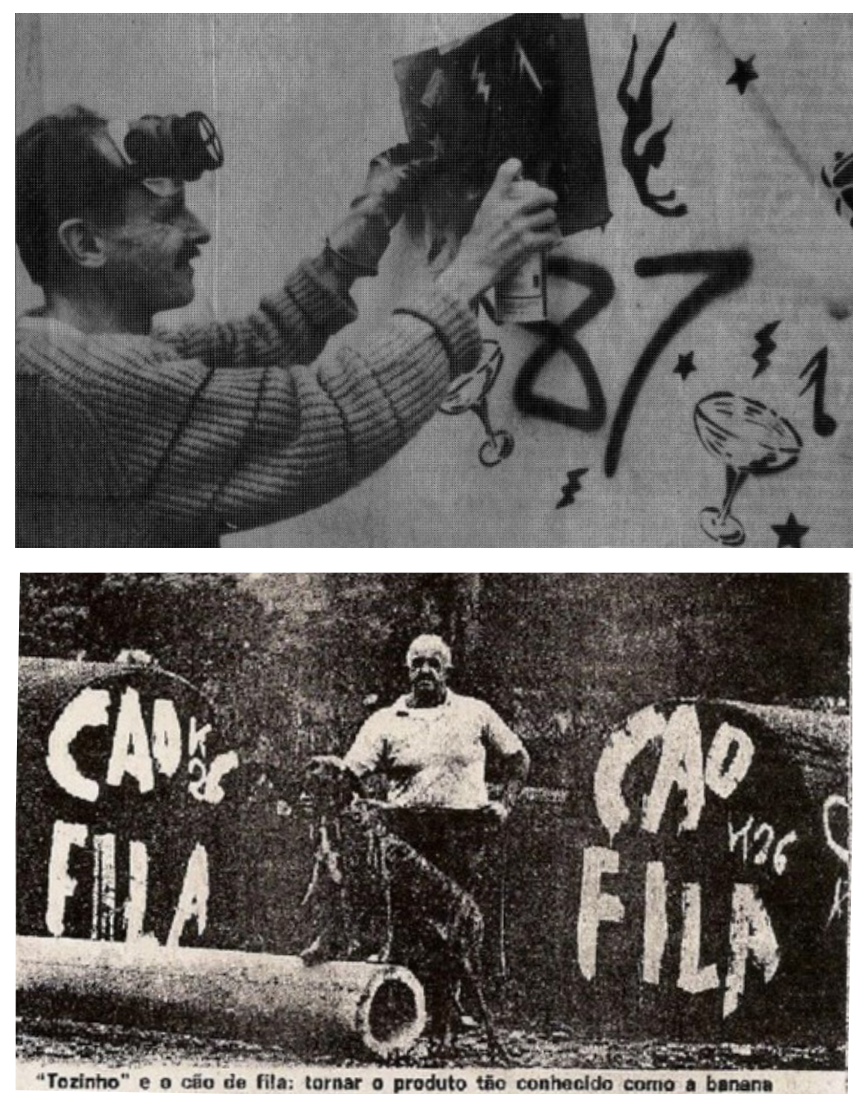

10 Imagens disponíveis respectivamente em <http://bit. ly/2sKkmBm> e $<$ http://bit.ly/2tXBXVI $>$.
Figura 3. Pixações na cidade de São Paulo.
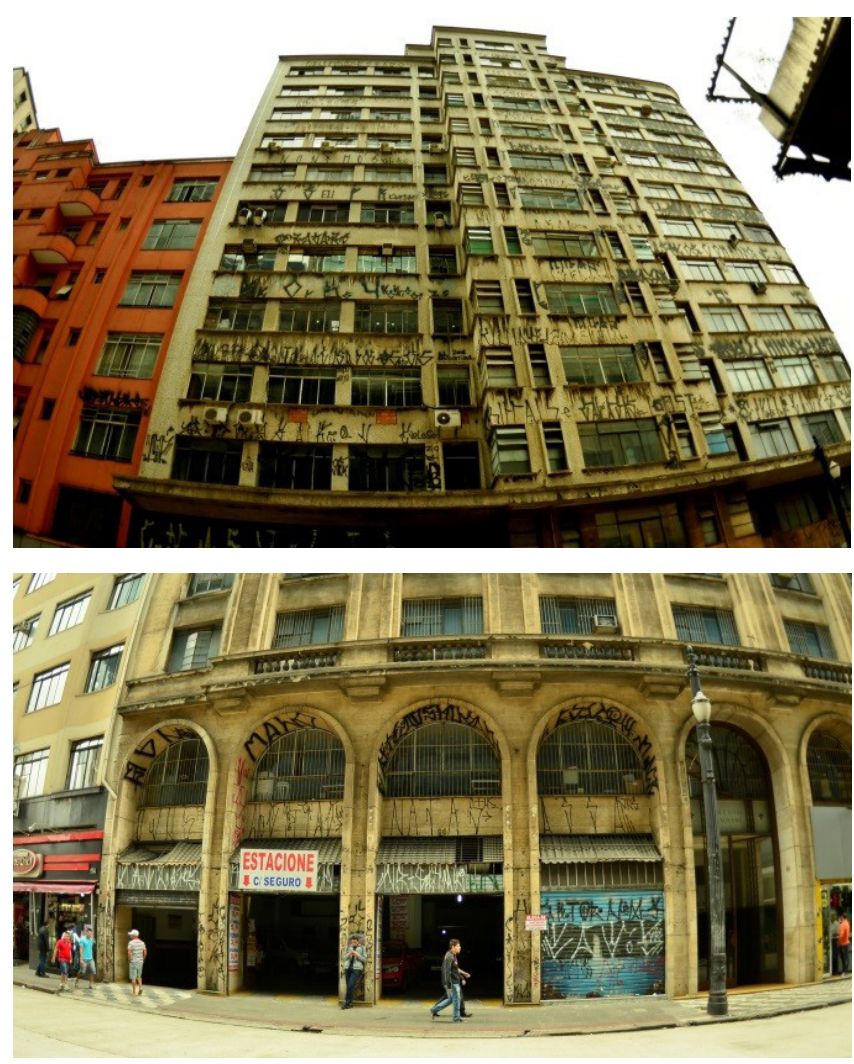

Fonte: Fotografias de Anderson Akio Shishito (outubro de 2015).

Já nos anos 1990, o grafite ampliou sua presença às periferias, seguindo o rastro do movimento Hip Hop. Assim como os outros elementos desse movimento, o grafite atendeu à vontade de falar às multidões por meio da arte, protestando contra as precárias condições de vida das periferias e subúrbios. No Hip Hop, o grafite é tido como o mais abrangente dos elementos (GOMES, 2012), diferenciando-se dos demais - e de outras manifestações culturais - por dialogar com seu público sem que o procurem.

Nesse cenário fértil e ainda em construção, o grafite brasileiro adquiriu singularidades que são reconhecidas/ valorizadas mundialmente ${ }^{11}$, atribuindo-lhe o status de

11 O grafite brasileiro é cada vez mais reconhecido no mundo e frequentemente artistas são convidados a importantes mostras e exposições de arte internacionais. A singularidade do grafite brasileiro vem de incorporar elementos da cultura regional com o uso de técnicas rudimentares que derivaram da "evolução técnica do improviso", oriundas de dificuldades que os artistas tiveram que enfrentar devido à escassez de materiais desenvolvidos especificamente para esse fim no Brasil do final do século XX (momento em que o grafite se iniciava no país). 
arte reconhecida, ou como é comum entre as publicações do gênero "street art".

\section{Entre a paisagem e cultura: a porção simbólica do espaço}

Por se tratar de um conceito "escorregadio", sobretudo devido a seu caráter polissêmico, delimitar a abrangência do conceito de paisagem não faz parte do escopo deste artigo.

Nos estudos da paisagem, são diversas as apropriações relacionadas ao conceito, áreas como história da arte (pintura de paisagem), arquitetura e urbanismo (paisagismo), movimentos ambientalistas (ecologia), turismo, literatura, entre outros, fazem o uso diferenciado do conceito.

Essa polissemia nos atesta a importância do conceito de paisagem e cabe à geografia ultrapassar visões simplistas no intuito de aprofundar a discussão sobe o tema.

Apoiamo-nos na análise desenvolvida por Cosgrove, um dos principais teóricos da Nova Geografia Cultural, que emerge a partir da década de 1970. Inicialmente, faz-se necessário discorrer de forma sucinta as premissas básicas que influenciaram o desenvolvimento epistemológico do autor.

Entre as contribuições dadas pelo autor está o diálogo do espaço geográfico com a cultura e o simbolismo nas paisagens humanas, fato bastante notório na afirmação presente no título de uma de suas principais obras: a geografia está em todos os lugares (COSGROVE, 1998). Essa reflexão faz oposição direta à geografia pautada no positivismo clássico ou no positivismo lógico presentes até então.

Name (2010, p. 177) traduz a dinâmica entre cultura e simbolismo em Cosgrove:

[...] a riqueza de sua abordagem está, por um lado, no fato de a paisagem ser revelada como a resultante de um processo, permanentemente inacabado; e, por outro lado, por ser assumidamente considerada como uma abstração - ela não existe per se, pois, como parte da "realidade", é uma maneira de se produzir, manipular e contemplar o espaço.

Outra preocupação de Cosgrove se vincula ao fato de que a geografia deveria se ocupar em se desvincular do puro funcionalismo utilitário da explicação geográfica estritamente prática e buscar atribuir em seu escopo analítico outros significados contidos na paisagem, como expressa na seguinte passagem: [existe] paixões inconvenientemente, às vezes assustadoramente poderosas, motivadoras da ação humana, entre elas as morais, patrióticas, religiosas, sexuais e políticas. Todos sabemos quão fundamentalmente estas motivações influenciam nosso comportamento diário. [...] Contudo na geografia humana parecemos intencionalmente ignorá-las ou negá-las. [...] nossa geografia deixa escapar muito do significado contido na paisagem humana tendendo a reduzi-la a uma impressão impessoal de forças demográficas e econômicas. (COSGROVE, 1998, p. 222, grifo do autor)

Desse modo, a proposta desenvolvida é de uma geografia humanizada em sua concepção, ou seja, busca-se tratar a geografia como humanidade e ciência social.

Cabe ressaltar que, além das questões relacionadas ao simbolismo e à cultura, também se subscreve ao pensamento de Cosgrove um forte teor crítico, sobretudo na abordagem feita sobre a relação entre cultura e poder na produção das paisagens. Ao discorrer que existem culturas dominantes e alternativas, o impacto de cada uma delas na paisagem humana se dará de forma diferenciada. Cria-se, assim, uma relação de submissão e dominação entre as paisagens.

A paisagem da cultura dominante exibe o poder da classe dominante, constituindo-se como marca identitária. Trata-se da subjetivação da paisagem propagada por grupos ou classes que detêm os meios de controle de vida: capital, terra, matéria-prima e força de trabalho. Segundo Cosgrove (1998, p. 230):

Seu poder é mantido e reproduzido, até um ponto consideravelmente importante, por sua capacidade de projetar e comunicar, por quaisquer meios disponíveis e por todos os outros níveis e divisões sociais, uma imagem do mundo consoante com sua própria experiência e ter essa imagem aceita como reflexo verdadeiro da realidade de cada um. Esse é o significado da ideologia.

Descolada da apropriação ideológica da cultura dominante, as culturas alternativas são menos visíveis, ou melhor, é necessário fazer um exercício de escala para percebê-las. Em algumas ocasiões, elas tendem a parecer dominantes, porém, como pontua Cosgrove (1998, p. 233), "por mais dominante localmente que possa ser uma cultura alternativa, ela continua subdominante à cultura nacional oficial".

No desenvolvimento das paisagens alternativas, o autor divide essa categoria em três subgrupos: 
i. paisagens residuais: são símbolos nas paisagens que contêm, em sua materialidade, uma carga simbólica que nem sempre é a mesma do uso contemporâneo, pois são interpretadas por outras suposições culturais em relação ao significado original;

ii. paisagens emergentes: apesar do caráter transitório e de impacto efêmero, as paisagens emergentes possuem suas geografias e seus sistemas de símbolos próprios. São as paisagens emergentes que irão desafiar as culturas dominantes, pois funcionam como porções do espaço propositivas a um futuro alternativo: uma paisagem utópica;

iii. paisagens excluídas: como indica o termo, é a exclusão de uma cultura tratada como marginal, refere-se à simbologia incidida na paisagem por grupos sociais periféricos do status quo mas que, mesmo assim, deixam como herança simbólica marcas riquíssimas na paisagem.

Assim, para Cosgrove, a paisagem deve ser interpretada de forma crítica, sem deixar de ressaltar seu lado simbólico e cultural, instigando a interpretação geográfica como na passagem a seguir:

As paisagens tomadas como verdadeiras de nossas vidas cotidianas estão cheias de significado. Grande parte da Geografia mais interessante está em decodificá-las. [...] Porque a geografia esta em toda parte, reproduzida diariamente por cada um de nós. A recuperação do significado em nossas paisagens comuns nos diz muito sobre nós mesmos. Uma geografia efetivamente humana crítica e relevante, que pode contribuir para o próprio núcleo de uma educação humanista: melhor conhecimento e compreensão de nós mesmos, dos outros e do mundo que compartilhamos. (COSGROVE, 1998, p. 236)

\section{Tipos de paisagem em Cosgrove: proposta de interpretação a partir do grafite}

Como supracitado, ao atribuir a dimensão cultural e simbólica ao conceito de paisagem, Cosgrove estabelece uma distinção entre a noção de paisagem dominante e paisagem alternativa.

Todas essas paisagens são dotadas de significados distintos, pois são criadas por diferentes grupos sociais. Nossa proposta de análise consiste em interpretar o local do grafite dentro da reflexão feita por Cosgrove no que se refere aos diferentes tipos de paisagem.

Discorreremos sobre possíveis interpretações do grafite em consonância com a teoria apresentada. Desse modo, direcionamos nossa explanação pontuando que o grafite, em sua essência, configura-se como marca de uma paisagem excluída por se tratar de uma ação de subversão desde sua origem. Como cultura, o grafite representa um conjunto de normas, ações, valores e ideologias referenciadas em uma prática ilegal de apropriação do espaço em revanche à norma social dominante. No entanto, é importante ressaltar que nem todo grafite é ilegal, assim como nem todo grafite tem natureza contestadora. Tratálo dessa maneira seria uma generalização irrelevante.

Dentro da lógica de paisagens excluídas, destacamos também a ação da pixação nas cidades. Apesar de não ser o objeto de estudo deste artigo, a pixação se enquadra nesse contexto por ser, assim como o grafite, uma forma de expressão simbólica de grupos sociais excluídos socialmente que, por meio de suas marcas na cidade, deixam um conjunto de simbologias singulares na paisagem.

O grafite, quando analisado por outro ângulo, também pode ser entendido como materialidade simbólica e cultural de paisagens emergentes. Nessa perspectiva, entendemos que pode proporcionar outro referencial paisagístico à cidade, fazendo frente à construção monótona, linear, monocromática e sem horizonte das grandes cidades. Ele expõe na paisagem urbana imagens em que o lúdico e a fantasia se fundem em um mundo utópico, no qual o multicolorido é a regra, a profusão de cores e formas quebra a noção geometrizada dos espaços hegemônicos.

Ainda como representação de paisagem emergente, podemos analisar o grafite como elo entre as pessoas e o lugar: estimulador de uma nova apropriação da paisagem urbana, ressignificando a noção de pertencimento da população local ao lugar, sobretudo nas periferias das cidades.

Como exemplo dessa ressignificação, observamos as ações do coletivo de grafite chamado Grupo Opni ${ }^{12}$. Formado em 1997, no bairro de São Mateus, zona Leste da capital paulista, esse grupo trabalha a arte e a cultura popular por meio de grafite, fotografia e cultura hip hop.

12 Durante sua trajetória, a sigla que dá nome ao coletivo já teve diversas conotações, como Objetos Pixadores Não Identificados, Os Policiais Nos Incomodam, Ódio Produz Nossa Inspiração e Os Prezados Nada Importantes. Atualmente, o nome do coletivo não pretere definições, significando um grito de guerra pessoal que representa a periferia. 
A partir de aspectos da cultura afro-brasileira e atrelado ao cotidiano da comunidade onde cresceram, o Grupo Opni objetiva expressar a realidade do dia a dia, que os tornavam invisíveis para oportunidades e visíveis ou estereotipados para vários tipos de violências que permeiam as relações nos bairros pobres do Brasil.

Ao longo dos dezenove anos de existência, esse grupo contribuiu com importantes trabalhos socioculturais para a região de São Mateus. Entre os mais importantes estão a ONG São Mateus em Movimento ${ }^{13}$ e a Galeria a Céu Aberto ${ }^{14}$, além da participação em importantes eventos de arte no Brasil e no exterior, ressaltando em seus trabalhos os olhares e necessidades do cotidiano periférico.

As ações desenvolvidas pelo Grupo Opni buscam promover transformação mútua entre o lugar e os agentes que lá atuam, protagonizando naquela paisagem subsídio para contrapor a lógica dominante que exclui seus integrantes e os impede de reivindicar seus direitos à cidade. (FIGURA 4)

Figura 4. Galeria a Céu Aberto, Vila Flávia, São Matheus (SP) ${ }^{15}$.
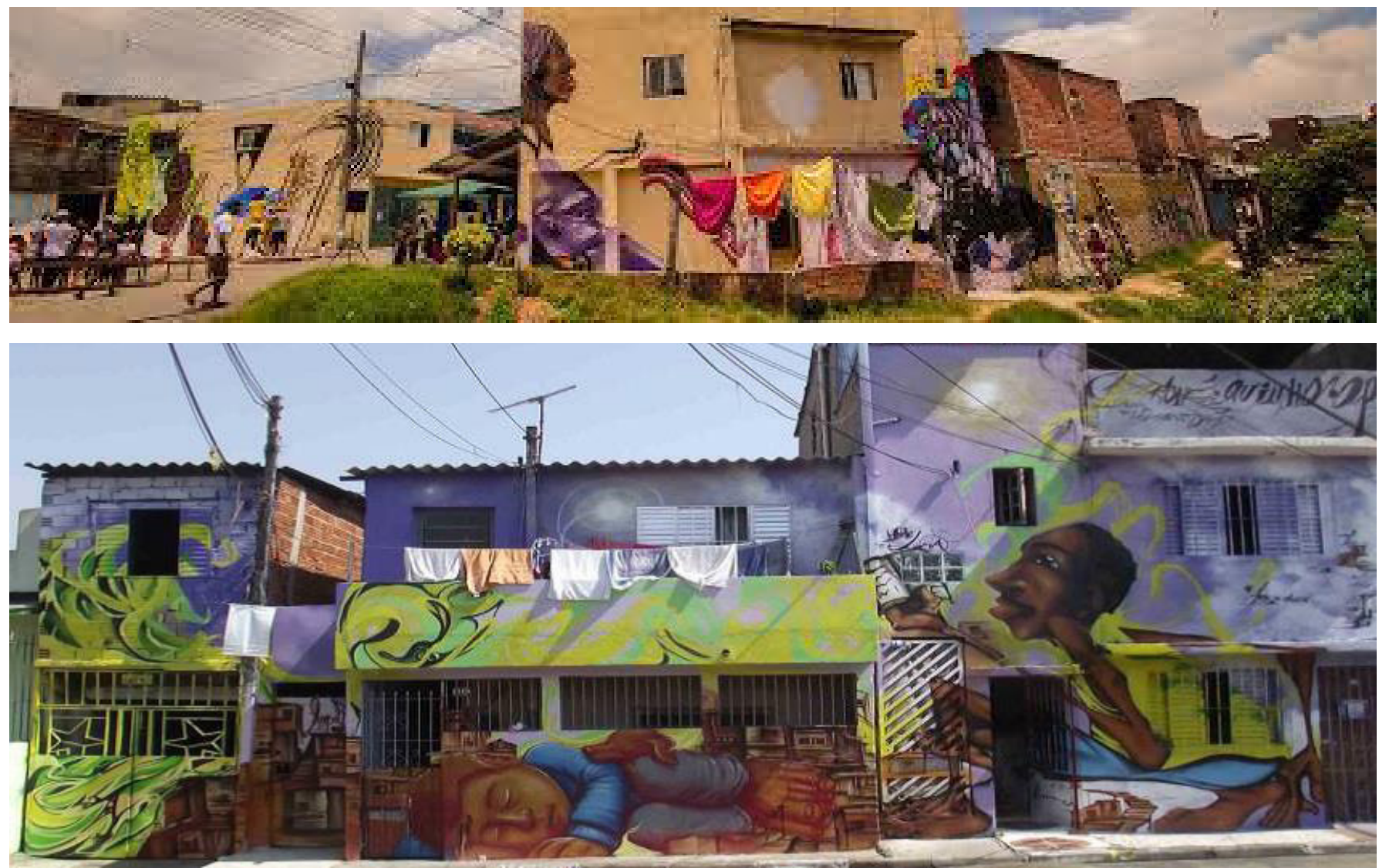

13 A ONG São Mateus em Movimento, que foi fundada com uma parceria entre coletivos em 2008, conquistou o status de maior articuladora cultural da região, oferecendo, além de apoio para os artistas, cursos e oficinas gratuitos de diferentes linguagens, para crianças e adolescentes. Nessas atividades, além das competências técnico-artísticas, também é abordada uma série de conteúdos transversais, como contexto histórico da região, desigualdade social, drogas, sexualidade etc.

14 A Galeria a Céu Aberto é fruto do projeto Favela Grafitada, desenvolvido pelo Grupo Opni desde 2009. O local onde está localizada a galeria é a Vila Flávia, inserida no distrito de São Mateus. Vale ressaltar que o percurso dessa galeria incide sobre uma Zona Especial de Interesse Social (ZEIS-8). A ideia central do projeto é grafitar todos os muros, cantos, vielas e casas, transformando o bairro em uma grande galeria de arte urbana. Atualmente, a galeria conta com aproximadamente duzentas intervenções de grafite. O processo de curadoria das intervenções é desenvolvido pelo próprio Grupo Opni, que já trouxe para as ruas e vielas da comunidade algumas das principais referências nacionais (Finok, Miau, Zefix, Binho, Chivitz, Minhau e Tika) e internacionais do grafite (Shalak, do Canadá; Shonis e Aspi, da Argentina; Ayslap e Baster, do Chile; Sato, da Espanha; Beli, da Bélgica; Atsuo, do Japão; e Joel, dos Estados Unidos).

15 Imagens disponíveis no site <http://site.grupoopni.com.br/>. 


\section{CONSIDERAÇÕES FINAIS}

A ação do grafite nos muros da cidade é um ato que instaura uma linguagem no espaço público. Uma atitude que surge do desencantamento com a imagem habitual da urbe por meio do aspecto de uniformidade visual e paisagística. Suas cores revelam o desejo de estabelecer outra realidade, uma realidade paralela, mas com tendência a se tornar soberana.

A conexão entre a materialidade do grafite e o conceito de paisagem desenvolvida por Cosgrove aparece neste artigo como lócus privilegiado e ainda aberto para novas análises mais profundas sobre a competência da geografia.

\section{REFERÊNCIAS}

CARLOS, A. F. A. A (re)produção do espaço urbano. São Paulo: Edusp, 1994. 270 p.

CORRÊA, R. L. O espaço urbano. São Paulo: Ática, 2004. (Série Princípios).

COSGROVE, D. A geografia está em toda parte: cultura e simbolismo nas paisagens humanas. In: CORRÊA,
R. L.; ROZENDAHL, Z. (Orgs.). Paisagem, tempo e cultura. Rio de Janeiro: Eduerj, 1998. p. 222-236.

GITAHY, C. O que é graffiti. São Paulo: Brasiliense, 1999. v. 312. (Coleção Primeiros Passos).

GOMES, R. L. Território usado e movimento hip hop: cada canto um rap, cada rap um canto. 2012. 159 f. Dissertação (Mestrado em Geografia) - Instituto de Geociências, Universidade Estadual de Campinas, Campinas, 2012.

MITTMANN, D. O sujeito-pixador: tensões acerca da prática da pichação paulista. 2012. 125 f. Dissertação (Mestrado em Educação) - Instituto de Biociências, Universidade Estadual Paulista "Júlio de Mesquita Filho", Rio Claro, 2012.

NAME, L. O conceito de paisagem na geografia e sua relação com o conceito de cultura. GeoTextos, Salvador, v. 6, n. 2, p. 163-186, dez. 2010.

OLIVEIRA, D. A.; TARTAGLIA, L. Ensaio sobre uma geo-grafia dos graffitis. GEOgraphia, Niterói, v. 11, n. 22, p. 59-88, 2009. 